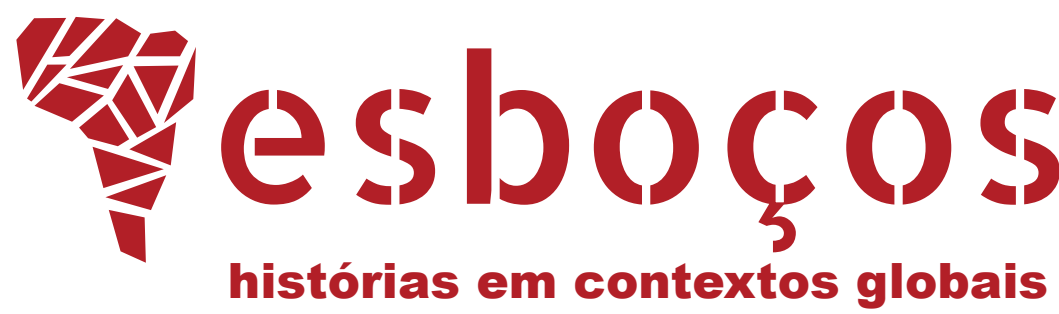

\title{
ORIGENS SOCIAIS E ARRANJOS MATRIMONIAIS DE UMA FAMÍLIA DE IMIGRANTES PORTUGUESES: A GENEALOGIA DOS VIEIRA DOS SANTOS (C. 1750-1820)
}

Social Origins and Marriage Alliances of a Portuguese Immigrant Family: the Vieira dos Santos Genealogy (c. 1750-1820)

Sandro Aramis Richter Gomes ${ }^{\mathrm{a}}$ (10) http://orcid.org/0000-0002-6790-4958 E-mail: argomes8@gmail.com

André Luiz Moscaleski Cavazzani ${ }^{b}$ (D) https://orcid.org/0000-0003-1512-3639 E-mail: andrexcava@gmail.com

a Universidade Federal do Paraná, Setor de Ciências Humanas, Programa de Pós-Graduação em História, Paraná, PR, Brasil

${ }^{\mathrm{b}}$ Centro Universitário Internacional Uninter, Departamento de Linguagens e Sociedade, Curso de História, Paraná, PR, Brasil 


\title{
RESUMO
}

Este artigo comporta uma investigação sobre a natureza das ocupações profissionais e dos vínculos matrimoniais de três gerações da família Vieira dos Santos. Essa parentela de origem portuguesa contava com membros que imigraram para o sul da capitania de São Paulo no fim do século XVIII. Há três argumentos sustentados nesta análise. Primeiro, é evidenciado que a formação dessa parentela foi decorrente da absorção, por meio do casamento, de indivíduos que exerciam profissões como a de agricultor e ourives. Segundo, cumpre evidenciar que a vinda para o Brasil não gerou a permanência dos imigrantes nas ocupações dos seus ascendentes. A mudança para tal colônia portuguesa ocasionou o ingresso dos membros daquela família no comércio e em esferas da administração pública. Terceiro, é demonstrado que, no Brasil, os integrantes dessa parentela mantiveram uma prática adotada por seus ascendentes. Tal prática era selecionar padrinhos pertencentes a um mesmo grupo profissional. Os Vieira dos Santos radicados em Portugal e no Brasil empregaram análogas estratégias familiares. Uma consequência dessas estratégias foi reforçar o pertencimento dessa parentela a círculos sociais compostos por artífices e comerciantes.

\section{PALAVRAS-CHAVE}

Artífices. Esquemas matrimoniais. Imigração portuguesa.

\begin{abstract}
The present article investigates the nature of professional occupations and marriage relationships of three generations of the Vieira dos Santos family. This family of Portuguese origin had members who immigrated to the south of the Captaincy of São Paulo in the late eighteenth century. There are three arguments supported by this analysis. First, it is evidenced that the formation of this kinship was due to the absorption, through marriage, of individuals who exercised professions such as that of farmer and goldsmiths. Secondly, it should be pointed out that coming to Brazil did not generate their permanence in the occupations of their ancestors. The settlement in this Portuguese colony led to the entry of members of that family into commerce and into the spheres of public administration. Third, it is clear that, in Brazil, the members of this family maintained a practice adopted by their ascendants. This practice was to choose sponsors belonging to the same professional group. In Portugal and Brazil, the members of this family applied similar social strategies. A consequence of these strategies was to reinforce their presence in social circles composed of artisans and merchants.
\end{abstract}

\section{KEYWORDS}

Artificers. Marriage Alliances. Portuguese Immigration. 
presente artigo comporta uma investigação acerca das alianças matrimoniais e da condição social de três gerações de uma parentela estabelecida no Noroeste de Portugal, no contexto da segunda metade do século XVIII e das primeiras duas décadas do XIX. Trata-se da família Vieira dos Santos, cujos membros, em sua maior parte, eram provenientes da vila de Fânzeres. No período em tela, tal vila era uma freguesia pertencente à jurisdição do município do Porto.

O objetivo central deste artigo é a produção de um conhecimento sobre perfis e origens sociais de imigrantes que se estabeleceram numa área do litoral sul da capitania de São Paulo no fim do século XVIII. Tal área atualmente pertence à jurisdição do estado do Paraná. A identificação das práticas econômicas dos familiares desses imigrantes permite evidenciar as circunstâncias sociais em que eles, os imigrantes que se radicaram no litoral sul paulista, se encontravam no momento de sua transferência para o Brasil. Os resultados apresentados no decorrer deste artigo subsidiam uma compreensão sobre a posição de parentes desses imigrantes na hierarquia social de uma área do noroeste português: o distrito do Porto.

O artigo é iniciado por uma análise sobre as ocupações profissionais exercidas por ascendentes e parentes colaterais paternos do autor das informações genealógicas estudadas neste artigo: o comerciante Antônio Vieira dos Santos (17841854), portuense que se estabeleceu no Brasil em fins do século XVIII. ${ }^{1}$ Nesse âmbito, é destacado que as ocupações predominantes desses ascendentes e parentes colaterais eram a agricultura e os ofícios artesanais, notadamente a ourivesaria.

Por consequência, é analisada a natureza das ocupações profissionais de ascendentes e parentes colaterais maternos de Antônio Vieira dos Santos. A ourivesaria e a agricultura também eram as ocupações mais recorrentes desses parentes maternos. As informações sobre os ramos materno e paterno da parentela do genealogista permitem asseverar que os arranjos matrimoniais nos quais estavam envolvidos Ihes permitiram o estabelecimento de vínculos familiares com membros do próprio grupo profissional.

Em seguida, é dedicada atenção ao perfil profissional dos padrinhos dos filhos de Jerônimo Vieira dos Santos (1758-1834), pai de Antônio Vieira dos Santos. Nesse estágio da abordagem, é demonstrado que o estabelecimento de relações de compadrio permitiu a consolidação da presença dos Vieira dos Santos num circuito de relações sociais composto por ourives e negociantes. Portanto, cumpre sustentar o argumento de que tal parentela, no início do século XIX, estava integrada a três esferas da vida econômica portuguesa: a agricultura, o artesanato e o comércio.

\footnotetext{
${ }^{1}$ Antônio Vieira dos Santos nasceu na cidade do Porto. Era filho de Jerônimo Vieira dos Santos, lavrante de prata, e Ana Joaquina, proveniente de uma parentela composta por lavradores, ourives e militares. O citado imigrante se transferiu para a cidade do Rio de Janeiro em 1797. No ano seguinte, radicou-se na vila litorânea de Paranaguá, à época pertencente à jurisdição da capitania de São Paulo. Nesse município, Antônio dos Santos atuou como comerciante varejista. Em 1814, fixou-se na freguesia de Morretes, situada na área litorânea do atual estado do Paraná. Nessa sociedade, o citado imigrante se dedicou ao beneficiamento da erva-mate. Faleceu em Morretes, em 1854. Esse imigrante desempenhou postos na administração desse município, como o cargo de vereador. Antônio dos Santos, portanto, enquadra-se na categoria de um português que ingressou num círculo social composto por integrantes de elites locais de uma área do extremo sul paulista. A respeito da trajetória de Antônio Vieira dos Santos em sociedades do litoral do atual estado do Paraná, ver Costa (1988) e Cavazzani (2015). Concernente à vida social e econômica do litoral paranaense de meados do século XIX, ver Leandro (2003).
} 
Por fim, é realizada a análise das ocupações profissionais exercidas pelos familiares maternos e paternos de Leonarda Batista de Moura Vilela (1769-1844), madrasta do genealogista. A identificação dessas ocupações permite salientar que a segunda esposa de Jerônimo Vieira era proveniente de uma família marcada pela diversificação de suas atividades profissionais. A atuação na agricultura, no comércio e na vida militar foi comum a distintos membros dessa parentela. De modo análogo aos Vieira dos Santos, a família Vilela conheceu reveses econômicos nas décadas finais do século XVIII.

A fonte empregada neste artigo consiste num conjunto de três árvores genealógicas produzidas por Antônio Vieira dos Santos. Essas árvores contêm informações sobre ancestrais e parentes colaterais do pai, da mãe e da madrasta do genealogista. Esses textos de conteúdo genealógico estão inseridos no primeiro volume das memórias de Antônio dos Santos. Tal volume é intitulado Breve resumo dos sucessos mais notáveis acontecidos desde 1797 até 1827. As informações genealógicas ali encontradas foram redigidas no fim dos anos $1820 .^{2}$

Tais árvores genealógicas foram produzidas na época em que Antônio dos Santos manteve correspondência epistolar com os familiares que permaneceram em Portugal. Por meio da leitura de Breve resumo dos sucessos, nota-se que, no decorrer dos anos 1820, tal imigrante recebeu, de forma contínua, cartas do pai e dos irmãos. Após duas décadas da sua transferência para o Brasil, Antônio dos Santos continuava a ser informado sobre nascimentos, casamentos e falecimentos dos parentes que viviam naquele país (SANTOS, 1827, p. 171-201). Em suma, a confecção das três árvores genealógicas utilizadas neste artigo foi uma decorrência da comunicação assídua entre o imigrante e seus familiares. Ao mesmo tempo, foi nos anos 1820 que Antônio dos Santos começou a desenvolver a prática de escrever textos memorialísticos. ${ }^{3}$ Além de discorrer sobre a própria trajetória, buscou reconstituir a origem de sua família por meio da produção de árvores genealógicas. Nesse contexto, tornou-se reconhecido por membros da elite social de Morretes como um comerciante dotado de conhecimentos sobre a escrita de textos políticos e literários (SANTOS, 1950, p. 360). A elaboração de trabalhos genealógicos por Antônio dos Santos não foi circunscrita aos anos 1820. Ele cultivou tal prática até o início dos anos $1850 .{ }^{4}$ Portanto, a fonte aqui estudada data do período em que o referido imigrante começou a se dedicar de maneira permanente à produção de obras de conteúdo histórico.

A historiografia referente aos artífices portugueses do século XVIII tem conferido pouca ênfase à condição econômica e social dos indivíduos que se ocupavam da ourivesaria. Nesse quadro, o estudo dos impactos de conjunturas econômicas nas

\footnotetext{
${ }^{2}$ Esse volume de memórias está sob a guarda do Círculo de Estudos Bandeirantes (Curitiba, Rua XV de Novembro, 1050).

${ }^{3}$ A prática de escrever textos memorialísticos foi cultivada por Antônio dos Santos até o início dos anos 1850. Além de Breve resumo dos sucessos, ele redigiu uma obra intitulada Memórias dos sucessos mais notáveis acontecidos desde o ano 1838. Tal obra contém informações que abrangem os anos de 1838 a 1851, mas não comporta informações genealógicas. O manuscrito dessas memórias está sob a guarda do Círculo de Estudos Bandeirantes. Para o conhecimento da relação completa das obras escritas por Antônio dos Santos, ver Negrão (2004).

${ }^{4}$ Em 1852, Antônio dos Santos preparou Árvore genealógica das famílias Freire e França. Tais parentelas estavam radicadas no litoral do atual Paraná (NEGRÃO, 2004). Esse texto genealógico, contudo, permanece extraviado.
} 
formas de produção e comércio da joalheria portuguesa não consta como elemento basilar da historiografia referente ao Portugal setecentista. Há maior atenção às mudanças nas técnicas da produção de joias (OREY, 1995; SOUSA, 2000; SILVA, 2008). Em verdade, é um aspecto secular da historiografia portuguesa o estudo de aspectos e das mudanças da técnica de confecção de joias (VASCONCELOS, 1912).

A historiografia também permanece carente de análises sobre os fatores que geravam desigualdades entre os artífices no que concerne à sua posição social e ao seu poder econômico. Assim, mantém-se pouco desenvolvida a compreensão de causas e impactos dos reveses econômicos experimentados por tais profissionais no Portugal setecentista. Em síntese, é pouco usual a investigação das diferenças sociais entre os artesãos (SOUSA, 1999; 2004; 2005). De sua parte, o presente artigo evidencia, por meio de um estudo de caso, que houve específicos padrões de alianças sociais e familiares nos quais os artífices do noroeste de Portugal estavam envolvidos.

No que diz respeito a essa região portuguesa, a historiografia dedicou maior atenção ao estudo da constituição de alianças familiares no decorrer dos séculos XVIII e XIX. Trata-se, pois, de uma corrente de abordagem que propicia a compreensão das formas de reprodução social que ali vigoraram (SCOTT, 2012). Nesse âmbito, compete desenvolver uma investigação que avance no entendimento sobre a condição social das famílias do noroeste português cujos membros migraram para o Brasil. Tal abordagem torna viável o conhecimento das práticas econômicas e das formas de constituição de vínculos familiares dos portugueses que permaneceram no Reino e dos seus compatriotas que se estabeleceram na colônia.

Por outro lado, a historiografia sobre a imigração portuguesa em áreas sulinas do Brasil se mantém pouco avançada. Há, pois, maior ênfase no estudo sobre a inserção e a mobilidade social de açorianos na capitania do Rio Grande do Sul, no contexto do século XVIII (BERUTE; SCOTT; SCOTT, 2017; HAMEISTER, 2006; MARQUES, 2012; QUEIROZ, 1992). Referente ao estado do Paraná, o estudo sobre a imigração foi centrado no reconhecimento dos impactos dos contatos entre adventícios e os membros da sociedade receptora no decorrer do século XIX (BALHANA, 1978; BIDEAU; NADALIN, 2011; MACHADO, 1998).

Nos estudos sobre imigração europeia em tal estado, é pouco comum a análise de percursos sociais de imigrantes pertencentes a um mesmo grupo familiar (STOLLMEIER, 2016). Assim, o avanço propiciado pelo presente artigo consiste em reconhecer as características dos processos de formação de alianças matrimoniais e os modos de enraizamento social de uma parentela cujos membros, no fim do século XVIII, fixaram residência em municípios do Brasil meridional.

Em suma, continua pouco desenvolvido o estudo da integração de imigrantes europeus na hierarquia social de municípios do atual estado do Paraná (COLATUSSO, 2004). Nesse âmbito, permanece mais avançada a análise dos fatores que ocasionaram a formação e a conservação dos vínculos sociais entre os imigrantes na sociedade receptora (SCARPIM, 2010). Mantém-se incipiente, portanto, a produção de análises sobre as circunstâncias econômicas que determinaram a migração de portugueses para o Sul do Brasil em fins da época colonial.

Ao mesmo tempo, permanece em estágio pouco desenvolvido o conhecimento dos processos de mobilidade social de reinóis na área que corresponde ao litoral paranaense. O presente artigo, por sua vez, permite um entendimento a respeito das formas de acomodação de reinóis numa sociedade do extremo sul da capitania de São 
Paulo. Em suma, esta investigação possibilita a compreensão acerca das iniciativas de jovens adventícios para obter uma ocupação profissional e adentrar os esquemas matrimoniais de uma sociedade colonial.

\section{OS PERCURSOS SOCIAIS DE FAMILIARES PATERNOS DE ANTÔNIO VIEIRA DOS SANTOS: A RELAÇÃO ENTRE OS ESPAÇOS RURAL E URBANO NO NOROESTE PORTUGUÊS}

Nesta seção do artigo, é evidenciada que a migração para a área urbana, especialmente a cidade do Porto, era uma pretensão de ascendentes paternos de Antônio Vieira dos Santos. A migração era uma estratégia que possibilitava a obtenção de aprendizado em ofícios artesanais, sobretudo a ourivesaria.

De outra parte, é demonstrado que os arranjos matrimoniais nos quais os familiares de Antônio Vieira dos Santos estavam envolvidos permitiram consolidar os vínculos dessa parentela com indivíduos dedicados à agricultura e ao artesanato. Desse modo, no decorrer da segunda metade do século XVIII, os Vieira dos Santos não evadiram por completo do espaço rural.

Por fim, os parentes de Antônio dos Santos que se radicaram no Brasil em fins da época colonial não se ocuparam, na sociedade receptora, dos mesmos ofícios cultivados por seus ascendentes. A carpintaria, a ourivesaria e a agricultura não constam no rol de ocupações desempenhadas por Antônio dos Santos e seus parentes em distintas capitanias do Brasil. Esses indivíduos, ao mesmo tempo que se estabeleceram no litoral sul paulista, não estavam treinados em algum ofício artesanal.

As informações analisadas nesta seção estão contidas no Quadro 1. Os mais longínquos ancestrais paternos mencionados por Antônio dos Santos são seus avós Gonçalo dos Santos e Maria Vieira, que eram artesãos. Gonçalo exercia a profissão de carpinteiro. Maria, por seu turno, era tecedeira (SANTOS, 1827, p. 65-66). Assim, a atenção às profissões desempenhadas por esses ascendentes permite evidenciar a relação entre a ocupação econômica e o funcionamento de arranjos matrimoniais. A formação desse casal significou a aproximação entre indivíduos dedicados a ocupações artesanais.

A geração dos avós paternos do genealogista cultivava a prática de migrar de uma freguesia portuense para outra. Esse era o limite de sua mobilidade espacial. Gonçalo dos Santos, por exemplo, evadiu da freguesia de Carneiro e se fixou na de Fânzeres, onde faleceu (SANTOS, 1827, p. 65). Tal característica foi preservada pela geração dos pais de Antônio dos Santos. Em verdade, foi a partir da geração do próprio genealogista que as migrações na família Vieira dos Santos se tornaram mais frequentes.

Os matrimônios contraídos pelos filhos e pelos netos de Gonçalo dos Santos permitiram consolidar o pertencimento de sua parentela junto a um grupo social composto por artífices radicados na área mais central da cidade do Porto e na freguesia portuense de Fânzeres. Em 1767, tal freguesia era composta por 350 fogos. Em 1788, era dotada de 362 casas (SANTOS, 1827, p. 206). Em 1874, por fim, já tinha 510 residências (LEAL, 1874, p. 174). Assim, num intervalo de 107 anos, Fânzeres conheceu um aumento de $45 \%$ no seu número de fogos.

Os membros da família Vieira dos Santos, em resumo, estavam inseridos numa freguesia que experimentou um crescimento espacial vagaroso no decorrer 
de um século. Nesse contexto, os esquemas matrimoniais dos quais os Vieira dos Santos participavam no noroeste de Portugal ocasionaram a permanência de integrantes dessa família no espaço rural. A esse respeito, atente-se para as informações do Quadro 1.

Quadro 1 - Ocupações profissionais dos familiares paternos de Antônio Vieira dos Santos ${ }^{5}$

\begin{tabular}{|c|c|c|}
\hline $\begin{array}{c}\text { Grau de parentesco com } \\
\text { Antônio Vieira dos Santos }\end{array}$ & Ocupação & Quantidade \\
\hline Avô & Carpinteiro & 1 \\
\hline Avó & Tecedeira & 1 \\
\hline Cunhado & Ourives & 1 \\
\hline Pai & Lavrante de prata & 1 \\
\hline Prima consanguínea & Tecedeira & 1 \\
\hline Primo consanguíneo & Carpinteiro & 1 \\
\hline Primo consanguíneo & Lavrador & 1 \\
\hline Primo consanguíneo & Funcionário público & 1 \\
\hline Primo consanguíneo & Escrevente de tabelionato & 1 \\
\hline Primo por afinidade & Carpinteiro & 1 \\
\hline Primo por afinidade & Comerciante & 1 \\
\hline Tia consanguínea & Tecedeira & 1 \\
\hline Tia por afinidade & Tecedeira & 1 \\
\hline Tio consanguíneo & Ourives & 1 \\
\hline Tio consanguíneo & Lavrador & 1 \\
\hline Tio consanguíneo & Tecelão & 1 \\
\hline Tio por afinidade & Lavrador & 2 \\
\hline Tia-avó por afinidade & Lavradora & 1 \\
\hline Tio-avô por afinidade & Lavrador & 1 \\
\hline & sadra & 1 \\
\hline
\end{tabular}

Fonte: Santos (1827, p. 65-77).

A análise do quadro acima reproduzido evidencia que, no fim do século XVIII e no início do XIX, havia um predomínio de descendentes de Gonçalo dos Santos no exercício de ocupações urbanas. De todo modo, duas irmãs de Gonçalo eram casadas com indivíduos que se enquadravam na categoria de lavradores. Uma filha desse carpinteiro também contraiu núpcias com um agricultor. Por fim, um dos netos de Gonçalo dos Santos também estava enraizado em área rural e foi enquadrado pelo genealogista como um lavrador (SANTOS, 1827, p. 66).

No referido recorte temporal, havia a tendência de filhos de Gonçalo dos Santos a migrarem da freguesia de Fânzeres para a área mais central da cidade do Porto. Conforme informado na genealogia confeccionada por Antônio dos Santos, dois filhos

\footnotetext{
${ }^{5}$ Nos Quadros 1 e 2, a expressão primo por afinidade se refere aos maridos das primas de Antônio Vieira dos Santos. As expressões tia/tio por afinidade são referentes, por seu turno, às esposas e aos maridos de tios e tias consanguíneos de Antônio Vieira dos Santos. No Quadro 4, a expressão primo por afinidade faz referência ao esposo de uma prima de Leonarda Vilela.
} 
se transferiram para o Porto com a finalidade de aprender as técnicas de um ramo do artesanato. Tal ramo era o ofício de produzir utensílios de prata.

De acordo com o genealogista, os irmãos Manuel e Jerônimo Vieira dos Santos se tornaram lavrantes de prata após migrarem da freguesia de Fânzeres para a cidade do Porto. O início do aprendizado de Manuel Vieira nesse ofício ocorreu em 1763, quando ele tinha dez anos. Jerônimo Vieira, por sua vez, foi iniciado nos misteres do artesanato em 1772, quando estava com a idade de catorze anos (SANTOS, 1827, p. 67-68).

Jerônimo, contudo, não prosperou em tal profissão. Sua trajetória contém evidências de que não era incomum, no noroeste português, que um artífice mudasse de ocupação. Antônio dos Santos informou que Jerônimo abandonou tal ofício em 1795, após 23 anos do início de seu treinamento em tal serviço. Entre os decênios de 1790 e 1820, desempenhou as funções de coletor de impostos, fiel de forno de bolacha e condutor de mantimentos entre as cidades do Porto e de Coimbra (SANTOS, 1827, p. 95). Em 1815, esse antigo artífice foi admitido para o posto de guarda da alfândega do Porto. Em 1825, por fim, Jerônimo já havia mudado de ocupação, passando a atuar como comerciante de vinhos nessa cidade. Em 1827, continuava a exercer esse ofício (SANTOS, 1827, p. 96).

A mudança de ocupação profissional foi acompanhada pela circulação entre as freguesias do Porto. Ele viveu, por exemplo, em São João da Foz do Douro de 1816 a 1820 (SANTOS, 1827, p. 95). Durante três décadas, portanto, Jerônimo oscilou entre a atuação como comerciante autônomo e o trabalho em órgãos do Estado. Desse modo, quando estava na faixa dos sessenta anos, havia se acomodado na condição de comerciante varejista. Nesse quadro, a vivência de adversidades no exercício de ocupações profissionais, no âmbito da família Vieira dos Santos, implicava a deflagração de precisas estratégias. A mudança de ocupação profissional era uma iniciativa decorrente de insucessos econômicos. Conforme demonstrado neste artigo, tal mudança também foi peculiar aos percursos dos filhos de Jerônimo que se radicaram no Brasil.

Jerônimo Vieira costumava não permanecer por um longo período num mesmo endereço. Eram frequentes as suas mudanças de residência no interior da cidade do Porto. Entre 1784 e 1815, mudou treze vezes de domicílio (SANTOS, 1827, p. 97). Tais informações consistem em evidências de que não pertencia ao grupo de artífices do Porto que se distinguiam pelo comando das oficinas que acolhiam aprendizes e funcionavam de modo estável.

Em suma, o perfil social do pai de Antônio dos Santos era o de um indivíduo que não pertencia à elite dos artesãos do noroeste português. O abandono do ofício de lavrante de prata implicou o desempenho intermitente de distintas ocupações urbanas, sobretudo aquelas ligadas ao comércio. Assim, na segunda metade do século XVIII e no início do XIX, os membros da família Vieira dos Santos eram dedicados tanto a atividades econômicas agrárias quanto a ocupações urbanas, em particular a ourivesaria. Houve integrantes de tal parentela que, na juventude, realizaram migrações internas com a finalidade de sair da freguesia de Fânzeres e obter, na região mais urbanizada da cidade do Porto, os conhecimentos necessários ao desenvolvimento dos misteres da joalheria.

A transferência de Antônio dos Santos para o Brasil ocorreu em 1797, num contexto em que seu pai estava a exercer ocupações urbanas de modo pouco duradouro. As informações contidas nos textos memorialísticos e genealógicos de 
Antônio dos Santos permitem afirmar que ele e seus irmãos não foram treinados nas lides do comércio por Jerônimo Vieira. Esse treinamento ocorreu do Brasil. Os imigrantes pertencentes a essa família se enquadravam no perfil predominante dos portugueses que imigraram para o Brasil entre o fim do século XVIII e o começo do XIX. Um dos aspectos desse perfil era a condição de jovem solteiro; outro, a inclinação para se radicar no espaço urbano e atuar em áreas do comércio (ROWLAND, 2000a).

Em Portugal, na referida época, não era incomum que jovens portugueses migrassem de uma freguesia para outra na tentativa de obter uma ocupação. Tal prática era recorrente entre os reinóis que não alcançaram uma condição econômica estável (SCOTT, 2012). Jerônimo Vieira, portanto, pertenceu ao grupo de portugueses que, no contexto do distrito do Porto, mudaram constantemente de freguesia. Ele fez parte do contingente dos portuenses que encontraram dificuldades para exercer uma profissão de forma permanente.

Aos jovens desprovidos de relevantes oportunidades econômicas, também existia a alternativa da mudança para o Brasil. Os estudos históricos têm destacado que era frequente o ingresso, nessa antiga colônia, de reinóis com alguma instrução. No início do século XIX, por exemplo, a maior parte dos imigrantes provenientes do norte de Portugal era alfabetizada (ROWLAND, 2000b). ${ }^{6}$ A obtenção de uma educação elementar era decisiva para que o imigrante conseguisse exercer no Brasil ocupações ligadas ao comércio. Uma dessas ocupações era o ofício de caixeiro (GORENSTEIN; MARTINHO, 1992).

A esse respeito, o principal investimento de Jerônimo na formação dos filhos consistiu em financiar a frequência deles em escolas de primeiras letras. Ele também financiou a permanência de um desses descendentes em aulas que habilitavam para o exercício da profissão de cirurgião (SANTOS, 1827, p. 101-141). Contudo, os membros dessa parentela que se radicaram no Brasil não receberam em Portugal o treinamento para os ofícios que desempenharam na sociedade receptora.

Os familiares paternos de Antônio dos Santos que migraram para o Brasil se aproximavam pelo fato de que ambicionaram se fixar no Rio de Janeiro. De fato, quatro primos de Antônio dos Santos realizaram esse objetivo. Um desses parentes, Antônio José, atuou como escrevente do tabelionato do Tribunal da Relação do Rio de Janeiro. Um filho homônimo desse indivíduo era funcionário desse Tribunal. Por fim, um terceiro primo consanguíneo, Vicente, era alferes da Companhia de Ordenanças da freguesia carioca da Candelária. Outro primo de Antônio dos Santos, Francisco José, também residiu no Rio de Janeiro no início dos anos 1800. Porém, o genealogista não mencionou a profissão que esse imigrante exerceu na sociedade receptora (SANTOS, 1827, p. 76-78).

Antônio dos Santos não obteve a oportunidade de ser treinado nas lides do comércio da então capital brasileira. Diante desse revés, migrou para a vila portuária de Paranaguá, situada no extremo sul da capitania de São Paulo. Nesse município, de 1798 a 1804, atuou como caixeiro de um negociante açoriano. Em seguida, foi proprietário de um armazém de farinha e molhados. Sua atuação como comerciante varejista se estendeu entre os anos de 1805 e 1812. Uma trajetória análoga foi desenvolvida por um irmão do genealogista. Tratava-se de João Vieira dos Santos

\footnotetext{
${ }^{6} \mathrm{~A}$ esse respeito, Henrique Rodrigues salientou que, no distrito de Viana do Castelo, situado no norte de Portugal, a emigração de analfabetos era rara até 1850 e nula de 1836 a 1847 (RODRIGUES, 1995).
} 
(1786-s/d). Após exercer a função de caixeiro de um negociante de Paranaguá, tornou-se sócio do irmão Antônio no referido armazém (SANTOS, 1827, p. 6).

João dos Santos migrou para o Brasil em 1800, três anos após o irmão Antônio tomar essa iniciativa. Assim, a migração para o Brasil foi realizada gradualmente pelos membros da família Vieira dos Santos. Em virtude de dificuldades econômicas, no entanto, os Vieira dos Santos se dispersaram por municípios sulinos. Nesse contexto, a falência comercial de João dos Santos em Paranaguá motivou sua transferência para a capitania do Rio Grande do Sul, em 1812. Ao se fixar lá, foi empregado numa estância, isto é, uma propriedade rural destinada à pecuária (SANTOS, 1827, p. 134). A adversidade econômica, portanto, exigiu que esse reinol realizasse uma migração interna e mudasse de profissão.

De sua parte, Antônio dos Santos se transferiu em 1814 para uma vila adjacente a Paranaguá, Morretes, em virtude do seu insucesso como comerciante (SANTOS, 1827, p. 21). Nessa localidade, foi negociante de erva-mate (SANTOS, 1827, p. 54-134). Dessa forma, a semelhança entre os percursos de Jerônimo Vieira e de seus filhos que residiram no Brasil diz respeito ao caráter instável do exercício de ocupações profissionais.

Em larga medida, o insucesso dos irmãos Santos para se tornarem comerciantes varejistas foi decorrente da necessidade de contrair sucessivos empréstimos para manter em atividade o armazém de farinha e molhados. O endividamento gerou a dependência econômica desses indivíduos em relação a personagens da elite social de Paranaguá (SANTOS, 1827, p. 15-21). Diante da impossibilidade de prosperarem nesse município, adotaram a estratégia de realizar uma migração interna e recomeçar a vida profissional em outra localidade.

Houve, pois, dois destinos comuns aos membros da família Vieira dos Santos que se transferiram para o Brasil no fim do século XVIII: a atuação no comércio varejista e a obtenção de emprego público na cidade do Rio de Janeiro. A pretensão inicial desses imigrantes era se radicar na capital da colônia. Porém, o malogro desse projeto os motivou a mudar para uma vila do litoral sul de São Paulo. Dessa forma, os Vieira dos Santos, quando se transferiram para o Brasil, não permaneceram próximos. Ao contrário, o insucesso de suas iniciativas econômicas determinou a dispersão dos integrantes da família por distintas capitanias, sobretudo aquelas situadas no sul da colônia.

No contexto da segunda metade do século XVIII, em Portugal, ascendentes e parentes colaterais de Antônio dos Santos estavam majoritariamente enraizados em área urbana. Os casamentos desses parentes consolidaram tal enraizamento. A inserção no grupo de artesãos do Porto foi aspecto inerente a essa parentela. Porém, em alguns casos, essa inserção foi pouco consistente. Tal afirmação é corroborada pelo fato de que o artífice Jerônimo Vieira mudou de profissão em diferentes ocasiões.

O envolvimento de membros dessa parentela nos misteres do artesanato não originou um projeto familiar de transmissão de conhecimentos na ourivesaria. Ao contrário, alguns jovens pertencentes a tal parentela adotaram estratégias como a migração para o Brasil. Isso os levou a desempenhar ocupações não cultivadas pelos seus ascendentes, a exemplo dos ofícios de caixeiro, comerciante autônomo e funcionário de órgão público. 


\section{INTEGRAÇÃO NA VIDA URBANA E ESQUEMAS MATRIMONIAIS: OS PERFIS SOCIAIS DE PARENTES DE ANA JOAQUINA PEREIRA}

No presente estágio do artigo, é realizada a sustentação de dois argumentos. De um lado, trata-se de demonstrar que os familiares maternos de Antônio dos Santos tiveram uma presença no meio rural. Essa presença continuava a existir quando Antônio dos Santos produziu sua genealogia. Nesse contexto, havia também a presença de membros dessa parentela na vida urbana do Porto. O exercício da ourivesaria, por exemplo, não era incomum entre os familiares de Ana Joaquina Pereira.

De outro lado, a existência de artífices e, em particular, de ourives na família de Ana Joaquina evidencia a relação entre ocupações profissionais e funcionamento de esquemas matrimoniais. Mais precisamente, as informações aqui analisadas contêm indícios de que Ana Joaquina participou de um mercado matrimonial composto por indivíduos que desempenharam ocupações análogas àquelas exercidas pelos integrantes da família Pereira. Nesse quadro, o casamento de Jerônimo Vieira dos Santos com Ana Joaquina significou uma aliança social entre parentelas nas quais havia indivíduos dedicados aos misteres da joalheria na cidade do Porto.

Os primeiros ascendentes maternos citados na genealogia elaborada por Antônio dos Santos eram seus avós Domingos Pereira e Ana Joaquina, cujo sobrenome não foi mencionado. Antônio dos Santos salientou que a avó materna nascera na freguesia de Santo Ildefonso, pertencente à jurisdição do Porto (SANTOS, 1827, p. 68). Portanto, um aspecto inerente aos percursos dos ascendentes maternos e paternos do genealogista era a constituição de laços sociais e familiares em diferentes freguesias portuenses. Desse modo, o casamento entre os pais de Antônio dos Santos decorreu da aproximação entre indivíduos originários das freguesias portuenses de Fânzeres e Santo Ildefonso.

De acordo com o genealogista, Domingos Pereira era um comerciante que tinha uma "grande loja de mercancia" na cidade do Porto (SANTOS, 1827, p. 79). Antônio dos Santos, portanto, situou o avô materno em posição superior à de um comerciante varejista. De outra parte, os lavradores mencionados no rol dos parentes maternos do genealogista eram seu tio-avô Manuel Pereira e os três filhos concebidos por este. Nota-se, assim, um caso de transmissão familiar de uma ocupação econômica.

De modo distinto à situação verificada na família de Gonçalo dos Santos, na genealogia dos Pereira não existem informações sobre migrações internas realizadas pelos integrantes dessa parentela no fim do século XVIII. Assim, não há registro de migrações que tinham por finalidade propiciar a aquisição de uma ocupação profissional em área urbana.

Em relação aos descendentes de Gonçalo dos Santos, os parentes de Domingos Pereira eram mais propensos a permanecer fixados na área habitada por seus ascendentes. Esses parentes também eram mais inclinados, em relação aos Vieira dos Santos, a desenvolver a prática de transmitir uma ocupação profissional de uma geração a outra. Respeitante à distribuição das ocupações profissionais na família Pereira, atente-se para as informações do Quadro 2: 
Quadro 2 - Ocupações profissionais dos familiares maternos de Antônio Vieira dos Santos

\begin{tabular}{|c|c|c|}
\hline $\begin{array}{c}\text { Grau de parentesco com } \\
\text { Antônio Vieira dos Santos }\end{array}$ & Ocupação & Quantidade \\
\hline Avô & Comerciante & 1 \\
\hline Tio & Padre & 1 \\
\hline Tio-avô & Lavrador & 1 \\
\hline Tio-avô por afinidade & Ourives & 1 \\
\hline Primo consanguíneo & Caixeiro & 3 \\
\hline Primo consanguíneo & Lavrador & 1 \\
\hline Primo consanguíneo & Ourives & 1 \\
\hline Primo consanguíneo & Militar & 1 \\
\hline Primo por afinidade & Ourives & 1 \\
\hline
\end{tabular}

Fonte: Santos (1827, p. 79-82).

A transmissão familiar de ocupação profissional foi também verificada no segmento dos Pereira que estava enraizado na cidade do Porto. A esse respeito, uma tia-avó de Antônio dos Santos, Maria Pereira, era casada com o ourives João Ferreira. Um dos filhos concebidos pelo casal, José Pereira, exerceu a profissão desempenhada pelo pai. Ele exerceu tal ocupação na cidade baiana de Salvador (SANTOS, 1827, p. 27). Dessa forma, o ourives José era um reinol que, quando se estabeleceu no Brasil, já estava treinado num ofício artesanal.

Entre os três ourives da família Pereira mencionados na genealogia de Antônio dos Santos, dois foram incorporados a tal parentela por meio do casamento. Algumas mulheres pertencentes a diferentes gerações dessa família contraíram matrimônio com joalheiros residentes na cidade do Porto (SANTOS, 1827, p. 81-82). Assim, a inserção de mulheres da família Pereira nos esquemas matrimoniais desse município possibilitou que tal parentela consolidasse vínculos sociais com indivíduos dedicados a ocupações urbanas, especialmente o artesanato. Nessa parentela, portanto, a ligação com a ourivesaria não era derivada de uma tradição familiar de exercício dessa profissão.

No âmbito da família Pereira, em suma, notou-se que, de uma geração a outra, foi mantida a inclinação para o estabelecimento de relações sociais com indivíduos ligados aos misteres da joalheria. Por outro lado, não ocorreu a conservação de membros dessa parentela numa posição proeminente na vida comercial. Ao contrário, houve um caso de descendente de Domingos Pereira que, no fim do século XVIII, estava em posição subalterna na hierarquia da vida comercial da cidade do Porto. Tratava-se de Francisco, neto de Domingos. Nos anos 1810, Francisco foi caixeiro, isto é, empregado de um comerciante. Seu patrão era Plácido Lino dos Santos Teixeira, que tinha o título de negociante-mor do Porto (SANTOS, 1827, p. 79).

Nesse contexto, negociante-mor era uma expressão honorífica atribuída aos comerciantes abastados e socialmente prestigiados (REVISTA LUSITANA, v. 37-38, 1939). Um dos principais negócios controlados por Plácido Teixeira era a fábrica de lanifícios, fundada em 1805 e situada na freguesia portuense de Lordelo do Ouro. Desse modo, esse negociante esteve envolvido numa iniciativa de produção industrial de tecidos no início do século XIX (CAPELA, 1975, p. 36). Em síntese, o exercício da 
ocupação de caixeiro permitiu a Francisco Pereira a aproximação com personagens da elite social portuense.

Em última instância, o envolvimento nos esquemas matrimoniais foi decisivo para a consolidação dos Pereira na vida urbana do município do Porto. Os profissionais que atuavam como ourives foram arregimentados a tal parentela por meio do casamento. Ao mesmo tempo, as informações extraídas da genealogia elaborada por Antônio dos Santos permitem destacar os limites do poder econômico de membros da família Pereira e dos indivíduos a ela incorporados.

Assim, ourives e lavrantes de prata integrados a tal família não pertenciam ao estrato superior da hierarquia dos artífices do Porto. Eles não eram os controladores de oficinas compostas por um séquito de aprendizes. No âmbito dos ramos materno e paterno da família de Vieira dos Santos, no período referente às duas primeiras décadas do século XIX, não estava em curso um projeto de transmissão familiar de ofícios artesanais e mercantis. Ao mesmo tempo, os membros da família Pereira não se conservaram, no contexto das lides comerciais da cidade do Porto, como prestigiados negociantes. Aos membros dessa parentela que almejaram atuar no comércio, foi necessária a aceitação de uma condição social menos elevada: a de caixeiro.

\section{RELAÇÕES DE COMPADRIO EAMPLIAÇÃO DE VÍNCULOS SOCIAIS: OS PERFIS PROFISSIONAIS DOS PADRINHOS DOS FILHOS DE JERÔNIMO VIEIRA DOS SANTOS}

Neste estágio do artigo, é sustentado o argumento de que Jerônimo Vieira dos Santos consolidou vínculos sociais com artífices e comerciantes da cidade do Porto por meio de relações de compadrio. Esse antigo lavrante de prata teve onze filhos. Os batizados de seus descendentes foram ocasiões que reforçaram os vínculos de Jerônimo com indivíduos que pertenciam ao seu grupo profissional. Assim, à medida que ele passava a exercer outro ofício, ocorria a modificação no perfil profissional dos novos padrinhos dos seus filhos.

Ao mesmo tempo, a constituição de relações de compadrio foi determinante para a concretização do pertencimento de membros da família Vieira dos Santos no Brasil. Essas relações foram estabelecidas com indivíduos dedicados ao comércio. Desse modo, a constituição de vínculos sociais e familiares, no caso dos Vieira dos Santos radicados no litoral sul da capitania de São Paulo, foi estabelecida prioritariamente com indivíduos que pertenciam a um mesmo grupo profissional.

Há tempos, os estudos antropológicos salientam que, na Península lbérica, a cerimônia do batizado adquiriu uma precisa função social. Nesse evento, os compadres formalizam perante a Igreja Católica um vínculo indissolúvel. Uma consequência do compadrio é a possibilidade de haver um auxílio recíproco e contínuo entre os pais e os padrinhos da criança que recebeu o sacramento do batismo (GUDEMAN, 1971, 1975). ${ }^{7}$

\footnotetext{
${ }^{7}$ A relevância social dos laços de compadrio também se verificou na América espanhola. A historiografia tem salientado que, do fim do século XVIII a meados do XIX, em áreas como a província de Buenos Aires, o compadrio era uma prática crucial para a consolidação e a ampliação de redes sociais (SANTILLI, 2009).
} 
De igual modo, a historiografia tem evidenciado que a prática do compadrio é um elemento típico das sociedades do Antigo Regime. As relações sociais, em tal contexto, assumem um aspecto hierarquizado e corporativo. A referida prática propicia a formação de relações de solidariedade entre desiguais. Ela também reforça o pertencimento de um indivíduo ao corpo social (ENGEMANN, 2005).

Em Portugal, a adoção da prática do compadrio permitiu que os Vieira dos Santos estreitassem os vínculos com integrantes de um mesmo grupo profissional. No Brasil, o estabelecimento de tais laços favoreceu a aproximação entre membros dessa parentela e outros imigrantes de origem portuguesa. Nesse particular, trata-se de evidenciar que os Vieira dos Santos empregaram precisos critérios para a seleção de seus compadres.

Jerônimo Vieira dos Santos contraiu núpcias em duas ocasiões. Na primeira, casou-se com Ana Joaquina Pereira, em 1780. Após o falecimento dela, em 1789, ele desposou Leonarda Batista de Moura Vilela. O segundo casamento de Jerônimo Vieira aconteceu em 1792. No primeiro matrimônio, esse artífice concebeu quatro filhos; no segundo, sete. Na genealogia elaborada por Antônio dos Santos, há informações sobre as ocupações de catorze padrinhos dos filhos de Jerônimo. Concernente a tais profissões, atente-se para o Quadro 3.

Quadro 3 - Ocupações profissionais dos padrinhos dos filhos de Jerônimo Vieira dos Santos

\begin{tabular}{|c|c|c|}
\hline Ocupação do padrinho & Quantidade & $\begin{array}{c}\text { Esposa de Jerônimo Vieira ao } \\
\text { tempo do batismo }\end{array}$ \\
\hline Negociante & 4 & Leonarda de Moura Vilela \\
\hline Médico & 1 & Leonarda de Moura Vilela \\
\hline $\begin{array}{c}\text { Função na hierarquia da Igreja } \\
\text { Católica }\end{array}$ & 4 & Leonarda de Moura Viela \\
\hline Militar & 1 & Leonarda de Moura Vilela \\
\hline Ourives & 4 & Ana Joaquina Pereira \\
\hline
\end{tabular}

Fonte: Santos (1827, p. 69-80).

Entre os seis homens que batizaram filhos de Ana Joaquina e Jerônimo dos Santos, quatro exerciam a profissão de ourives. Os demais não tiveram as ocupações informadas (SANTOS, 1827, p. 71). Nesse contexto, Maria Rita, madrinha da última filha de Ana Joaquina e Jerônimo, era casada com um ourives residente no Porto (SANTOS, 1827, p. 72). O marido de Maria Rita não era compadre de Jerônimo. Essa informação denota que, para além dos ourives escolhidos por Jerônimo para apadrinhar os filhos, havia outros joalheiros que pertenciam ao círculo das relações familiares dos Vieira dos Santos naquela cidade.

As informações presentes na genealogia de Antônio dos Santos evidenciam que não havia uma diferença social marcante entre Jerônimo Vieira e os padrinhos de seus filhos nascidos do primeiro casamento. Ou seja, esse lavrante de prata não constituiu vínculos de compadrio com indivíduos superiormente posicionados na hierarquia social. Era equânime a posição social que aquele artífice e seus compadres conquistaram na cidade do Porto entre os anos de 1784, data do nascimento do filho 
primogênito de Jerônimo, e 1789, época do nascimento do último descendente oriundo das primeiras núpcias desse artífice (SANTOS, 1827, p. 72).

Os nascimentos decorrentes do segundo matrimônio de Jerônimo Vieira ocorreram entre 1793 e 1810. Nesse contexto, houve maior diversificação do perfil social e profissional dos padrinhos. Os mais frequentes eram os comerciantes, grupo ao qual Jerônimo passou a pertencer no começo do século XIX. Entre os padrinhos selecionados, também havia indivíduos que pertenciam à hierarquia da Igreja Católica. Nesse contexto, os filhos de Jerônimo e Leonarda foram apadrinhados por um abade, uma freira e dois padres (SANTOS, 1827, p. 73-74).

Em 1793, a primeira filha de Jerônimo e Leonarda foi batizada por um militar. Tratava-se de Pedro da Cunha Vaz Ferreira, que na ocasião era sargento-mor graduado do $2^{\circ}$ Regimento de Infantaria do Porto (REINO DE PORTUGAL, 1794, p. 4). Tal informação evidencia que o segundo casamento de Jerônimo lhe permitiu, desde o nascimento da primeira filha com Leonarda, diversificar o perfil social dos seus compadres.

De outra parte, a genealogia de Antônio dos Santos apresenta evidências de que o grupo de compadres de Jerônimo não era composto por indivíduos oriundos de diferentes áreas do noroeste português; era limitada a mobilidade espacial desses padrinhos. Assim, foi após se tornar compadre de Jerônimo que o citado Pedro Ferreira obteve outros postos militares e mudou de cidade. No início dos anos 1800 , ele foi tenente-coronel do Regimento de Milícias do município da Maia, que dista cerca de dez quilômetros do Porto (SANTOS, 1827, p. 73).

Em Portugal, do fim do século XVIII ao limiar do XIX, os Vieira dos Santos tinham um restrito envolvimento no comércio varejista. Todavia, conseguiram estabelecer conexões sociais com indivíduos que atuaram nesse ramo da vida econômica. Por meio das informações do Quadro 3, nota-se que a consolidação de relações de compadrio foi decisiva para que os integrantes dessa parentela adentrassem o círculo de relações sociais de comerciantes e artífices.

Por outro lado, quando o genealogista Antônio dos Santos se estabeleceu no Brasil, a constituição de relações de compadrio lhe foi estratégica para ampliar seus vínculos com o grupo mercantil da vila de Paranaguá. Os cinco filhos daquele imigrante que foram batizados nesse município litorâneo, entre 1805 e 1813, tiveram como padrinhos indivíduos que se dedicavam ao comércio varejista (SANTOS, 1827, p. 70).

Tal grupo de padrinhos era também formado por homens de origem portuguesa que se estabeleceram no litoral sul paulista nas décadas finais do século XVIII. Esses imigrantes eram os reinóis Manuel Antônio Pereira (1782-1857) e Manuel Francisco Correia (1776-1864), bem como o açoriano João Ferreira de Oliveira (1758-1809), sogro de Antônio dos Santos (SANTOS, 1827, p. 5). ${ }^{8}$ Em 1809, o filho concebido por João Vieira dos Santos e sua esposa Joaquina Maria Ferreira também foi apadrinhado por João Ferreira de Oliveira (SANTOS, 1827, p. 71).

No período em tela, no Brasil, o compadrio permanecia como um laço que tornava mais consistente o pertencimento a determinado grupo social. Essa função do compadrio se consolidou na época colonial e continuou a vigorar ao longo do século

\footnotetext{
${ }^{8}$ Para o conhecimento sobre as relações familiares constituídas pelos Vieira dos Santos no Brasil a partir da segunda metade do século XIX, ver Negrão (2004).
} 
XIX (BRÜGGER, 2007). Um aspecto do processo de enraizamento social dos irmãos Antônio e João Vieira dos Santos no Brasil consistiu em se manterem próximos de indivíduos que eram, ao mesmo tempo, compatriotas e membros de um mesmo grupo profissional. No Brasil, portanto, eles adotaram uma prática cultivada pelo pai, a qual consistia em selecionar padrinhos no interior do seu grupo profissional.

As citadas informações sobre os batizados dos filhos de Antônio e José Vieira dos Santos evidenciam que o compadrio permitiu que os imigrantes pertencentes a tal parentela se tornassem mais próximos de comerciantes radicados no litoral sul paulista. Ele possibilitou que os citados irmãos formalizassem uma aliança social com imigrantes que já tinham uma condição econômica estável.

Antônio e José Vieira dos Santos se tornaram compadres de João Ferreira de Oliveira, que era irmão do negociante Francisco Ferreira de Oliveira, antigo patrão de Antônio dos Santos. Esse laço de compadrio consolidou uma relação entre imigrantes que não ocupavam posições idênticas na hierarquia da sociedade receptora. Essa desigualdade derivava do fato de que, nessa época, os irmãos Ferreira de Oliveira já haviam consolidado um pertencimento à elite social do município de Paranaguá (SANTOS, 1827).

Dessa forma, as práticas familiares adotadas pelos Vieira dos Santos no Brasil, no começo do século XIX, eram análogas àquelas realizadas pelos seus compatriotas que também emigraram de Portugal. Entre elas, estava o estabelecimento de ligações com compatrícios radicados havia mais tempo na sociedade receptora. Tais ligações favoreciam o enraizamento e a mobilidade social do jovem reinol (ROWLAND, 2007).

\section{PATENTES MILITARES E MOBILIDADE ESPACIAL: OS PERFIS PROFISSIONAIS DE PARENTES DE LEONARDA BATISTA DE MOURA VILELA}

Nesta seção do artigo, é demonstrado que os parentes da madrasta de Antônio dos Santos tinham uma presença mais relevante em órgãos militares do que no comércio e nas lides do artesanato. A inclinação para a carreira militar assegurou a alguns familiares de Leonarda Vilela o enraizamento na cidade de Lisboa. Em suma, na genealogia elaborada por Antônio dos Santos, a mobilidade espacial mais ampla é o elemento que diferencia a família de Leonarda em relação à parentela do seu esposo, Jerônimo Vieira. Ao mesmo tempo, o segundo casamento de Jerônimo Vieira não ocasionou a ampliação de seus vínculos com os membros do grupo profissional ao qual pertencia à época: os artífices dedicados aos misteres da joalheria. O matrimônio com Leonarda aproximou Jerônimo de uma parentela na qual a ocupação de ourives não era adotada com frequência.

Os ancestrais mais remotos de Leonarda Vilela citados por Antônio dos Santos eram seus avós maternos e paternos. Segundo o genealogista, os avós paternos de Leonarda se dedicavam à agricultura. Eles se enquadravam na categoria de lavradores. Antônio dos Santos também salientou que ascendentes e parentes colaterais dos avós maternos de Leonarda viviam em áreas rurais do distrito do Porto (SANTOS, 1827, p. 89). As informações apresentadas pelo genealogista permitem salientar que a presença no meio rural de familiares de Leonarda se tornou menos significativa a partir da geração seguinte à de seus avós. 
Referente às ocupações econômicas dos ramos materno e paterno da parentela da madrasta de Antônio dos Santos, cumpre dedicar atenção às informações do Quadro 4:

Quadro 4 - Ocupações profissionais dos familiares de Leonarda Batista de Moura Vilela, madrasta de Antônio Vieira dos Santos

\begin{tabular}{|c|c|c|}
\hline $\begin{array}{c}\text { Grau de parentesco com } \\
\text { Leonarda Batista de Moura } \\
\text { Vilela }\end{array}$ & Ocupação & Quantidade \\
\hline Avô materno & Professor régio & 1 \\
\hline Avô paterno & Lavrador & 1 \\
\hline Pai & Negociante & 1 \\
\hline Tio materno & Militar & 1 \\
\hline $\begin{array}{c}\text { Primo consanguíneo } \\
\text { (materno) }\end{array}$ & Militar & 1 \\
\hline $\begin{array}{c}\text { Primo consanguíneo (ramo } \\
\text { familiar não identificado) }\end{array}$ & Escrivão & 1 \\
\hline $\begin{array}{c}\text { Primo consanguíneo (ramo } \\
\text { familiar não identificado) }\end{array}$ & Militar & 1 \\
\hline $\begin{array}{c}\text { Primo por afinidade (ramo } \\
\text { familiar não mencionado) }\end{array}$ & Ourives & \\
\hline
\end{tabular}

Fonte: Santos (1827, p. 83-90).

O avô materno de Leonarda Vilela atuava como professor régio. Ou seja, tinha autorização do governo português para exercer a regência de turmas de ensino elementar. ${ }^{9} \mathrm{O}$ avô paterno, por sua vez, era um lavrador cujos ascendentes e parentes colaterais ocuparam o posto de almotacé no município do Porto. Em sua maior parte, os membros dessa parentela viviam na freguesia de Alpendurada, que está situada na jurisdição do distrito do Porto. Em 1788, tal freguesia tinha 280 casas e 708 habitantes (SANTOS, 1827, p. 206).

Essas informações permitem a elaboração de três constatações. A primeira diz respeito ao fato de que a condição de lavrador não significou o distanciamento dos ascendentes paternos de Leonarda Vilela da vida urbana. Tal condição não os impediu, por exemplo, de desempenhar um cargo municipal. Por um período não superior a dois meses, o almotacé tinha a tarefa de fiscalizar o comércio, a limpeza urbana e a ordem social. Tratava-se de um posto cujo acesso ocorria por meio de eleição (PEREIRA, 2001). Conforme a classificação empregada por Antônio dos Santos, os ascendentes maternos de Leonarda pertenciam ao grupo de moradores "de boa qualidade" de Alpendurada (SANTOS, 1827, p. 89). O genealogista, portanto, ressaltou a distinção social que os ascendentes de sua madrasta tinham nessa freguesia.

A segunda constatação afirma que Alpendurada era uma localidade pela qual Jerônimo Vieira dos Santos circulava desde a época anterior ao seu casamento com Leonarda. De acordo com o genealogista Antônio dos Santos, Jerônimo tinha terras

\footnotetext{
${ }^{9}$ Acerca das características e das mudanças no ensino elementar do Portugal setecentista, ver Cardoso (2014).
} 
nessa freguesia. Essas terras foram vendidas por volta de 1792, época do seu segundo matrimônio (SANTOS, 1827, p. 95). Portanto, nos anos imediatamente anteriores ao abandono da profissão de artífice, Jerônimo já acumulara alguns bens. Sua condição social, em tal contexto, era mais estável em relação àquela em que se acomodou nos primeiros anos do século XIX.

A terceira constatação diz respeito ao fato de que a circulação de Jerônimo por Alpendurada lhe possibilitou consolidar relações sociais com membros dessa localidade. Tais relações, por seu turno, geraram o ingresso do artífice no mercado matrimonial da freguesia. A esse respeito, às vésperas do seu casamento, Leonarda tinha 23 anos e vivia no Convento de Santa Clara, situado na jurisdição do Porto (SANTOS, 1827, p. 87). Dessa forma, os familiares da noviça articularam seu matrimônio com um proprietário de terras daquela freguesia. Esse casamento significou o vínculo de um artífice em declínio com uma mulher oriunda de uma parentela cujos membros alcançaram um grau de distinção social em virtude de fatores como o desempenho de um cargo municipal.

No contexto dos anos 1790, uma semelhança entre as famílias Vilela e Vieira dos Santos era derivada da vivência de reveses econômicos. Segundo o genealogista, o pai de Leonarda era um negociante que faliu em época anterior ao casamento da filha. Antes da falência, ele tinha bois, três casas na cidade do Porto e barcos no rio Douro (SANTOS, 1827, p. 86). Portanto, é factível considerar que tal matrimônio tenha aproximado duas famílias que não tinham condição social muito diferente. Em síntese, esse casamento uniu parentelas que, na segunda metade do século XVIII, no noroeste português, haviam acumulado um patrimônio. Todavia, as adversidades econômicas geraram a perda desses bens nos últimos anos daquele século.

$\mathrm{Na}$ genealogia de Antônio dos Santos, nota-se que a geração de Leonarda Vilela e de seus primos, cujos membros nasceram por volta dos anos 1760 , estavam inseridos no meio urbano. De outra parte, tal genealogia comporta indícios de que, ao menos desde a geração dos pais e dos tios de Leonarda, alguns membros de sua família realizaram migrações internas.

Há que salientar o fato de que, na parentela de Leonarda, houve casos de transmissão familiar de uma ocupação profissional. Na família Vieira dos Santos, essa transmissão consistia no exercício, de uma geração a outra, do ofício de lavrador. Na parentela de Leonarda, essa transmissão familiar era representada pela presença de membros de diferentes gerações em cargos militares. A esse respeito, atente-se para o caso de João Batista de Moura, tio materno de Leonarda.

João Batista foi membro do Regimento de Cavalaria de Lisboa, no contexto dos anos 1790. Essa atividade militar Ihe permitiu, portanto, evadir da cidade do Porto e fixar residência na capital portuguesa. Ou seja, ele se enraizou num município que dista cerca de trezentos quilômetros do Porto. De outra parte, o pertencimento àquele regimento Ihe possibilitou consolidar vínculos sociais em Lisboa. Foi nessa cidade, por exemplo, que o militar contraiu matrimônio (SANTOS, 1827, p. 85). Seus dois filhos, João Batista e José Maria, também seguiram carreira militar. João Batista atuou na Marinha portuguesa. Quando faleceu, em 1811, detinha a patente de cabo. José Maria exercia, em 1819, a função de cabo da Companhia de Milícias de Lisboa (SANTOS, 1827, p. 85).

A única menção a um ourives na família de Vilela foi realizada por ocasião do arrolamento das primas de Leonarda. Uma delas, cujo nome não foi citado por Antônio dos Santos, era casada com um ourives (SANTOS, 1827, p. 89). Portanto, a 
presença de um joalheiro nessa parentela não era decorrente de uma tradição familiar de atuação na ourivesaria. Tal presença, em verdade, resultou do envolvimento de uma parenta de Leonarda em esquemas matrimoniais compostos por artífices. Notase, assim, uma semelhança entre as famílias Pereira, da mãe do genealogista, e Vilela, de sua madrasta. A semelhança reside no fato de que as mulheres dessas famílias foram as responsáveis, por meio de seus casamentos, pela incorporação de joalheiros a tais parentelas.

A família da segunda esposa de Jerônimo Vieira não se caracterizava pela presença significativa de seus membros numa específica ocupação profissional. Foi a partir da geração de Leonarda que, no ramo materno de sua família, foi iniciada a prática da transmissão familiar de uma ocupação. Essa ocupação era o exercício de postos militares. De todo modo, no começo dos anos 1790, os familiares paternos e maternos de Leonarda se assemelhavam pelo fato de que estavam, em sua maior parte, integrados ao meio urbano do distrito do Porto. Nesse contexto, estava em curso o processo de mobilidade espacial de alguns de seus membros. O principal efeito dessa mobilidade consistiu no estabelecimento de vínculos familiares com indivíduos enraizados na capital portuguesa.

\section{CONSIDERAÇÕES FINAIS}

A finalidade deste artigo consistiu na produção de um conhecimento sobre os perfis sociais e profissionais dos familiares de Antônio Vieira dos Santos, comerciante português que se estabeleceu em Paranaguá, vila litorânea do sul da capitania de São Paulo, no fim do século XVIII. Em sentido amplo, o artigo buscou avançar na compreensão sobre a condição social de uma família cujos membros estiveram envolvidos nos processos migratórios para o Brasil do fim da época colonial. Nesse quadro, é necessário ressaltar os resultados centrais sobre o modo de atuação profissional dos Vieira dos Santos no Brasil e em Portugal, no contexto do fim do século XVIII até o princípio do XIX.

Foi demonstrado que o genealogista Antônio dos Santos estava vinculado a uma parentela dedicada a ocupações rurais e urbanas. Entre elas, destacava-se o exercício da ourivesaria. A trajetória de Jerônimo Vieira, pai do genealogista, comporta indícios de que não era incomum que artífices portuenses mudassem de profissão. Essa mudança não gerava, em todas as situações, o exercício permanente de uma nova ocupação. Ao contrário, poderia ocasionar a inserção do antigo artífice numa condição instável do ponto de vista econômico e profissional.

O estabelecimento de relações de compadrio de Jerônimo Vieira obedeceu a específicos padrões, que se alteravam à medida que aquele antigo artífice mudava de profissão. Desse modo, o critério que empregou para selecionar os padrinhos dos filhos consistia em convidar indivíduos que exercessem ocupações análogas àquelas que ele próprio desempenhava. No contexto em que atuou como lavrante de prata, a maior parte de seus filhos foi batizada por homens dedicados à ourivesaria. Ao mesmo tempo que exerceu a ocupação de comerciante, houve sensível diversificação do perfil profissional de seus compadres. Nesse novo momento de sua trajetória, selecionou indivíduos dedicados ao comércio.

As duas núpcias de Jerônimo Vieira dos Santos evidenciam que sua parentela estava envolvida em arranjos matrimoniais que favoreciam o encontro de cônjuges 
cujas famílias se distinguiam pela presença tanto no espaço rural quanto no urbano. Nesse particular, o segundo casamento de Jerônimo lhe possibilitou cultivar relações familiares com uma parentela que tinha membros radicados em diferentes cidades de Portugal, notadamente Lisboa e Porto.

Outra constatação central desteartigo afirma que, à época de seu estabelecimento no Brasil, os integrantes da família Vieira dos Santos tiveram de ser treinados em ofícios não cultivados por seus ancestrais. Por meio de um estudo de caso, a presente análise evidenciou que, no noroeste português do fim do século XVIII, havia famílias em que os artífices não educavam os filhos para exercer a profissão paterna. No Brasil, a ausência dessa instrução profissional impeliu os jovens imigrantes da família Vieira dos Santos a atuarem no comércio, bem como a se tornarem funcionários de órgãos públicos. Em suma, o treinamento profissional desses jovens foi realizado na sociedade receptora.

Por fim, foi salientada uma aproximação entre Jerônimo Vieira e os filhos que migraram para o Brasil. Tal aproximação reside no fato de que eles enxergaram no batizado dos seus descendentes a ocasião propícia para constituir vínculos com membros de seu grupo profissional. Dessa forma, ao se transferirem para o litoral sul da capitania de São Paulo, o genealogista e seu irmão encararam as relações de compadrio como um fator decisivo para consolidar o pertencimento a um círculo social composto per negociantes.

\section{REFERÊNCIAS}

BALHANA, Altiva. Santa Felicidade: uma paróquia vêneta no Brasil. Curitiba: Fundação Cultural, 1978.

BERUTE, Gabriel; SCOTT, Ana Silvia Volpi; SCOTT, Dario. Negócios em família: migração, comerciantes portugueses e suas redes (Porto Alegre, Rio Grande de São Pedro, séculos XVIII-XIX). Acervo: Revista do Arquivo Nacional, Rio de Janeiro, $\mathrm{n}$. 30, n. 1 , p. $105-120,2017$.

BIDEAU, Alain; NADALIN, Sérgio. Une communauté allemande au Brésil: de l'immigration aux contacts culturels, $\mathrm{XIX}^{\mathrm{e}}-\mathrm{XX} \mathrm{X}^{\mathrm{e}}$ siècle. Paris: Ined, 2011.

BRÜGGER, Silvia Maria Jardim. Escolhas de padrinhos e relações de poder: uma análise do compadrio em São João d'El Rey (1736-1850). In: CARVALHO, José Murilo de (org.). Nação e cidadania no Império: novos horizontes. Rio de Janeiro: Civilização Brasileira, 2007. p. 313-347.

CAPELA, José. A burguesia mercantil do Porto e suas colônias, 1834-1900. Porto: Afrontamento, 1975.

CARDOSO, Tereza Fachada Levy (org.). História da profissão docente no Brasil e em Portugal. Rio de Janeiro: Mauad, 2014.

CAVAZZANI, André Luiz Moscaleski. Tendo o sol por testemunha: população portuguesa na baía de Paranaguá (c. 1750-1830). São Paulo: Alameda, 2015. 
COLATUSSO, Denise. Imigrantes alemães na hierarquia de status da sociedade luso-brasileira (Curitiba, 1869 a 1889). 2004. 151 p. Dissertação (Mestrado em História) -Departamento de História, Universidade Federal do Paraná, Curitiba, 2004.

COSTA, Samuel Guimarães da. O último capitão-mor (1782-1857). Curitiba: Editora da Universidade Federal do Paraná, 1988.

ENGEMANN, Carlos. Da comunidade escrava e suas possibilidades, séculos XVIIXIX. In: FLORENTINO, Manolo (org.). Tráfico, cativeiro e liberdade: Rio de Janeiro, séculos XVII-XIX. Rio de Janeiro: Civilização Brasileira, 2005. p. 169-205.

GORENSTEIN, Riva; MARTINHO, Lenira Menezes. Negociantes e caixeiros na sociedade da Independência. Rio de Janeiro: Secretaria Municipal de Cultura, Turismo e Esportes, 1992.

GUDEMAN, Stephen. Spiritual Relationship and Selecting Godparent. Man, new series, London, v. 10, n. 2, p. 221-237, 1975.

GUDEMAN, Stephen. The compadrazgo as a reflection of the natural and spiritual person. Proceedings of the Royal Anthropological Institute of Great Britain and Ireland, London, n. 1971, p. 45-71, 1971.

HAMEISTER, Martha Daisson. Para dar calor à nova povoação: estratégias sociais e familiares a partir dos registros batismais da Vila do Rio Grande (c.1748-c. 1763). 2006. 474 p. Tese (Doutorado em História Social) - Departamento de História, Universidade Federal do Rio de Janeiro, Rio de Janeiro, 2006.

LEAL, Augusto Soares de d'Azevedo Barbosa de Pinho. Portugal Antigo e Moderno. Lisboa: Livraria de Matos Moreira e Cia., 1874.

LEANDRO, José Augusto. Gentes do grande mar redondo: riqueza e pobreza na Comarca de Paranaguá (1850-1888). 2006. 323 p. Tese (Doutorado em História Social) - Departamento de História, Universidade Federal de Santa Catarina, Florianópolis, 2003.

MACHADO, Cacilda. De uma família imigrante: sociabilidade e laços de parentesco. Curitiba: Aos Quatro Ventos, 1998.

MARQUES, Rachel. Por cima da carne seca: hierarquia e estratégias sociais no Rio Grande do Sul (c.1750-1820). 2012. 173 p. Dissertação (Mestrado em História) Departamento de História, Universidade Federal do Paraná, Curitiba, 2012.

NEGRÃO, Francisco. Genealogia paranaense. Vol. 3. Curitiba: Imprensa Oficial, 2004.

OREY, Leonor (dir.). Cinco séculos de joalharia. Londres: Zwemmer, 1995. 
PEREIRA, Magnus. O Almuthasib: considerações sobre o direito de almotaçaria nas cidades de Portugal e suas colônias. Revista Brasileira de História, São Paulo, v. 21, n. 42, p. 365-395, 2001.

QUEIROZ, Maria Bertulini de. Paróquia de São Pedro do Rio Grande: estudo de história demográfica (1737-1850). 1992. 416 p. Tese (Doutorado em História) Departamento de História, Universidade Federal do Paraná, Curitiba, 1992.

REINO DE PORTUGAL. Provimento militar. Gazeta de Lisboa, Lisboa, ano 80, n. 12, 17 out. 1794, Suplemento, p. 3.

Revista Lusitana, v. 37-38, 1939.

RODRIGUES, Henrique. Emigração e alfabetização: o Alto-Minho e a miragem do Brasil. Viana do Castelo: Governo Civil de Viana do Castelo, 1995.

ROWLAND, Robert. A cultura brasileira e os portugueses. In: ALMEIDA, Miguel Vale; BASTOS, Cristiana; FELDMAN-BIANCO, Bela (orgs.). Trânsitos coloniais: diálogos críticos luso-brasileiros. Campinas: Ed. da Unicamp, 2007. p. 373-383.

ROWLAND, Robert. Portugueses no Brasil Independente: processos e representações. Revista Oceanos, Lisboa, n. 44, p. 68-84, out.-dez. 2000a.

ROWLAND, Robert. Brasileiros do Minho: emigração, propriedade e família. In: BETHANCOURT, Francisco; CHAUDHURI, Kirti (orgs.). História da expansão portuguesa: do Brasil para a África. Vol. 4. Lisboa: Círculo de Leitores, 2000b. p. 324-347.

SANTILLI, Daniel Victor. Entre el clientelismo y el reforzamiento de vínculos: familia e padrinazco en Buenos Aires, 1780-1840. Revista de Demografía Histórica, Madrid, v. 27, n. 2, p. 111-148, 2009.

SANTOS, Antônio Vieira dos. Breve resumo dos sucessos mais notáveis acontecidos desde 1797 até 1827. Morretes: s/e, 1827.

SANTOS, Antônio Vieira dos. Memória histórica, cronológica, topográfica e descritiva de Morretes e do Porto de Cima. Curitiba: Museu Paranaense, 1950.

SCARPIM, Fábio. Bens simbólicos em laços de pertencimento: família, religiosidade e identidade étnica nas práticas de transmissão de nomes de batismo em um grupo de imigrantes italianos (Campo Largo-PR, 1878-1937). 2010. 230 p. Dissertação (Mestrado em História) - Departamento de História, Universidade Federal do Paraná, Curitiba, 2010.

SCOTT, Ana Sílvia Volpi. Famílias, formas de união e reprodução social no Noroeste português (séculos XVIII e XIX). São Leopoldo: Oikos; Editora da Unisinos, 2012. 
SILVA, Nuno Vassallo e. A ourivesaria entre Portugal e a Índia: do século XVI ao século XVIII. Lisboa: Santander Totta, 2008.

SOUSA, Ana Cristina. Metamorfoses do ouro e da prata: a ourivesaria tradicional no Noroeste de Portugal. Porto: Centro Regional de Artes Tradicionais, 2000.

SOUSA, Gonçalo de Vasconcelos e. A joalharia em Portugal: 1750-1825. Porto: Livraria Civilização Editora, 1999.

SOUSA, Gonçalo de Vasconcelos e. A ourivesaria da prata em Portugal e os mestres portuenses: história e sociabilidade (1750-1810). Porto: Edição do Autor, 2004

SOUSA, Gonçalo de Vasconcelos e. Dicionário de Ourives e Lavrantes da Prata do Porto: 1750-1825. Porto: Livraria Civilização Editora, 2005.

STOLLMEIER, Luara Antunes. Os Fontana: aspectos da experiência imigrante (1880-2015). Dissertação (Mestrado em Sociologia). 2016. 154 p. Departamento de Sociologia, Universidade Federal do Paraná, Curitiba, 2016.

VASCONCELOS, Joaquim de. História da ourivesaria e joalheria portuguesa. Porto: s/e, 1912.

\section{NOTAS}

\section{AUTORIA}

Sandro Aramis Richter Gomes: Doutor. Pós-doutorando, Universidade Federal do Paraná, Setor de Ciências Humanas, Programa de Pós-Graduação em História, Curitiba, PR, Brasil.

André Luiz Moscaleski Cavazzani: Doutor. Professor titular, Centro Universitário Internacional Uninter, Departamento de Linguagens e Sociedade, Curso de História, Curitiba, PR, Brasil.

\section{ENDEREÇO PARA CORRESPONDÊNCIA}

Sandro Aramis Richter Gomes. Rua General Carneiro, 460, Centro, 80060-000, Curitiba, PR, Brasil.

\section{ORIGEM DO ARTIGO}

A abordagem empreendida neste artigo foi originalmente desenvolvida por André Luiz Moscaleski Cavazzani na tese -Tendo o sol por testemunha: população portuguesa na baía de Paranaguá (c. 17501830), apresentada ao Programa de Pós-Graduação em História Social da Universidade de São Paulo, em 2013. O presente trabalho também comporta informações estudadas por Sandro Aramis Richter Gomes na dissertação - Descentralização e pragmatismo: condições sociais de produção das memórias históricas de Antônio Vieira dos Santos (Morretes e Paranaguá, décadas de 1840-1850), apresentada ao Programa de Pós-Graduação em História da Universidade Federal do Paraná, em 2012.

\section{AGRADECIMENTOS}

Ao professor Sebastião Ferrarini (in memoriam), agradecemos por ter viabilizado a consulta aos manuscritos de Antônio Vieira dos Santos que estão depositados no Círculo de Estudos Bandeirantes. À equipe técnica da Superintendência do Instituto do Patrimônio Histórico e Artístico Nacional (IPHAN) no Paraná, somos gratos pela digitalização dos manuscritos do referido memorialista. 


\section{FINANCIAMENTO}

Não se aplica.

\section{APROVAÇÃO DE COMITÊ DE ÉTICA EM PESQUISA}

Não se aplica.

\section{CONFLITO DE INTERESSES}

Não houve conflito de interesses.

\section{LICENÇA DE USO}

Este artigo está licenciado sob a Licença Creative Commons CC-BY. Com essa licença você pode compartilhar, adaptar, criar para qualquer fim, desde que atribua a autoria da obra.

\section{PUBLISHER}

Universidade Federal de Santa Catarina. Programa de Pós-Graduação em História. Portal de Periódicos UFSC. As ideias expressadas neste artigo são de responsabilidade de seus autores, não representando, necessariamente, a opinião dos editores ou da universidade.

\section{EDITORES}

Alex Degan

Beatriz Mamigonian

Fábio Augusto Morales

Flávia Florentino Varella (Editora-chefe)

Tiago Kramer de Oliveira

Waldomiro Lourenço da Silva Júnior

\section{HISTÓRICO}

Recebido em: 11 de fevereiro de 2019

Aprovado em: 01 de agosto de 2019

Como citar: GOMES, Sandro Aramis Richter; CAVAZZANI André Luiz Moscaleski. Origens sociais e arranjos matrimoniais de uma família de imigrantes portugueses: a genealogia dos Vieira dos Santos (c. 1750-1820). Esboços, Florianópolis, v. 26, n. 43, p. 549-572, set./dez. 2019. 